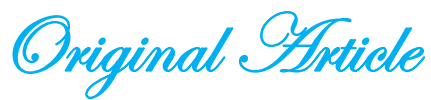

\title{
Anthropometric Evaluation of Nutritional Status for Patients with End-Stage Renal Disease in Sudanese Patients Elsharif M Elhafiz, ${ }^{1}$ Wala Eldin M Osman ${ }^{2}$, Elham Garib Alla ${ }^{2}$
}

Abstract:

Background: Malnutrition affecting 40 to $70 \%$ of patients with end-stage renal disease. Cause of malnutrition in patients with chronic renal disease include of a lower food intake, decreased intestinal absorption and digestion, and metabolic acidosis. The presence of malnutrition is usually suspected from anthropometry or the presence of hypoalbuminemia or decreased creatinine production. Anthropometric measurements provide a rapid, noninvasive, easy, and reproducible method for evaluating body fat and muscle mass.

Objective: The objective of the study is to assess the nutritional status of patients with ESRD on regular hemodialysis using anthropometric measurements.

Methodology: Prospective, cross-sectional, study was conducted in Gezira Hospital for Renal Diseases and Surgery on June 2010. 202 patients were joined in this study. Body mass index (BMI), triceps skinfold thickness, subscapular skinfold thickness and mid-arm circumference (MAC) were measured.

Results: $70.79 \%$ of the patients were having normal or high BMI while other anthropometric measurements were below the standard values in $66.83 \%$ of the patients. This result could be attributed to fluid retention.

Conclusion: Anthropometric measurements could be useful way for early detection malnutrition and follow up of nutritional status for patients on end-stage renal disease particularly in developing country.

Keywords: Anthropometry, nutrition, Hemodialysis, Sudan

$\mathrm{M}$ alnutrition affects 40 to $70 \%$ of patients with end-stage renal disease $(\mathrm{ESRD})^{1-10}$. Cause of malnutrition in patients with chronic kidney disease (CKD) include of a lower food intake, decreased intestinal absorption and digestion, and metabolic acidosis ${ }^{11-13}$. The dialysis itself is considered to be a catabolic procedure, due to reduced protein synthesis and the loss of amino acids in dialysate ${ }^{14}$. There is relationship between the dose of dialysis and protein intake ${ }^{15}$. Gastroparesis which occurs in 20 to $30 \%$ of patients with ESRD can be a contributing factor to the decreased food intake by delaying gastric emptying, thereby increasing the feeling of fullness ${ }^{16-18}$. patients with ESRD usually are taking drugs that can impair appetite or make meals less palatable.

1. Gezira hospital for renal Diseases

2. Ministry of Health

Correspondence To: drhafize@hotmail.com
The presence of malnutrition is usually suspected from anthropometry or the presence of hypoalbuminemia or decreased creatinine production. Anthropometric measurements provide a rapid, noninvasive, easily performed, and reproducible method for evaluating body fat and muscle mass. Body fat is estimated by measuring skin fold thickness at the triceps or subscapular area, while mid-arm circumference can provide an estimate of the muscle mass.

Because of the escalating numbers of patients with ESRD and lack of sufficient financial support we provide our patients two sessions of hemodialysis (HD) per week for four hours; which is below the recommended level by the National Kidney Foundation Dialysis Outcomes Quality Initiative (K/DOQI) and National Cooperative Dialysis Study $(\mathrm{NCDS})^{19-22}$. Inadequate dialysis has negative effect on nutritional status of the patients. The aim of the study is to assess the nutritional 
status of patients with ESRD on regular HD using anthropometric measurements.

\section{Methods and patients:-}

This prospective, cross-sectional, study was conducted in Gezira Hospital for Renal Diseases and Surgery on June 2010. 202 patients were recruited to this study. All our hemodiallysis patients are receiving HD session twice per week for four hours each due to financial causes. Data were collected by direct interview using standard questionnaire. Variables include: demographic data, length in meters, weight in $\mathrm{Kg}$ (to calculate body mass index (BMI)) and duration of HD. Triceps skinfold thickness, Subscapular skinfold thickness and Mid-arm circumference (MAC) were measured. The measurements at the upper arm were performed at the arm where arteriovenous is not located. The measurements were performed as following:

Mid-Arm Circumference: The measuring tape is placed around the upper arm at the mid of arm perpendicular to the long axis of the upper arm (+ from upper arm length). The tape is again held so that the zero end is held below the measurement value. The tape rests on the skin surface, but is not pulled tight enough to compress the skin. The arm circumference is recorded to the nearest $0.1 \mathrm{~cm}$.

Triceps skinfold: The point on the posterior surface of the upper arm is located in the same area as the marked midpoint for the upper arm circumference. A fold of skin and subcutaneous adipose tissue is grasped gently with thumb and fingers approximately $2.0 \mathrm{~cm}$ above the marked level with the skinfold parallel to the long axis of the arm. The jaws of the calipers are placed at the marked level, perpendicular to the length of the fold, and the skinfold thickness is measured to the nearest $0.1 \mathrm{~mm}$ while the fingers continue to hold the skinfold.

Subscapular skinfold: The examiner grasps a fold of skin and subcutaneous adipose tissue directly below $(1.0 \mathrm{~cm})$ and medial to the inferior angle. The skinfold forms a line about 45 degrees below the horizontal extending diagonally toward the right elbow the jaws of the caliper are placed perpendicular to the length of the fold about $2.0 \mathrm{~cm}$ lateral to the fingers with the top jaw of the caliper on the mark over the inferior angle of the scapula. The skinfold thickness is measured to the nearest $0.1 \mathrm{~mm}$ while the fingers continue to hold the skinfold.

The anthropometric measurements for nonHispanic blacks from National Health and Nutrition Examination Surveys (NHANES) were taken as standard due to lack of local well established anthropometric measurements data for Sudanese population.

Data were analyzed using the SPSS software (Statistical Package for the Social Sciences, version 17.0, SPSS Inc, and Chicago, Ill, USA). Continuous variables were presented as mean \pm standard deviation.

\section{Results:-}

Males represent $71.29 \%$ (144) of the study group. The mean age was $45.21 \pm 15.93$ years. The mean of height, weight and BMI were $166.14 \pm 9.78 \mathrm{~cm}, 58.24 \pm 11.96 \mathrm{~kg}$ and $21.21 \pm 9.78$ respectively. The mean MAC, Triceps skinfold and subscapular skinfold were found to be $2.285 \pm 3.97838 \mathrm{~cm}, 0.25 \pm$ $0.407 \mathrm{~cm}$ and $0.32 \pm .36$ below the nonHispanic blacks NHANES standard respectively.

$29.21 \%$ (59) of the patients were found to have BMI less than 18 and $14.85 \%$ (30) equal to or more than $25,55.94 \%$ (113) between 18 to 24.9 ; while $66.83 \%$ (135) had MAC, triceps skinfold and subscapular skinfold below NHANES standard. 4.46\% (9 had MAC, triceps skinfold and subscapular skinfold above NHANES standard.

\section{Discussion:}

This study investigated the nutritional status of ESRD patients on regular HD using anthropometric measurements. CKD is associated with a substantially increased incidence of congestive heart failure (CHF) and of atherosclerotic vascular disease events $^{23}$. Both CHF and inadequate HD could lead to fluid retention, and this may explain our finding regarding normal or high BMI in $71.43 \%$ of the patients while other anthropometric measurements was below the standard values in $67.86 \%$ of the patients; 
therefore BMI and weight are not good parameter for detection of malnutrition in patients with ESRD.

Providing ESRD patients with eight hours, three times per week HD is associated with the maintenance of normotension without medications in almost all patients. These results have been largely attributed to optimal volume control ${ }^{24-27}$.

Most of the Sudanese HD patients where provided with inadequate HD (two session per week) ${ }^{19}$.

There is no one measure which can be used in any patient population to accurately assess nutritional status; this is particularly true in renal failure. The plasma albumin, transferring, prealbumin and blood urea nitrogen concentration are commonly used to assess nutritional status in subjects with normal renal function ${ }^{6-9,28,29}$. Chung et al reported that patient survival rate is significantly lower in the malnourished. Early diagnosis and appropriate management of malnutrition may reduce the mortality and morbidity of $\mathrm{ESRD}^{30}$. In developing countries most of the patients cannot afford the cost of these investigations regularly; anthropometric measurements could be a useful alternative way for early detection of malnutrition and follow up of nutritional status of patients on HD.

In this report malnutrition of $67.86 \%$ in patients with ESRD on regular dialysis which is comparable to other part of world.in similar settings ${ }^{1-10}$ which could be attributed to inadequate hemodialysis since we offer two session of hemodialysis per week, gastroparesis $^{16-18}$, and psychological factors ${ }^{31}$. Detection of malnutrition patient's is team work and should be done as early as possible for prevention of severe consequence in morbidity and mortality. Anthropometric measurement could have great value in early detection especially in HD units with limited financial recourses.

Limitations of the current study are first the large variability of ethnic background of Sudanese patients and secondly the lack of national wide well recognized anthropometric standards for adults. A well-recognized

(C) Sudan JMS Vol. 6, No.2. Jun 2011 nationwide anthropometric standard is needed. Anthropometric measurements should be recorded regularly for all chronic patients particularly ESRD patients to assess the nutritional status. Adequate dialysis should be provide to all patients on HD

\section{References:-}

1. Thunberg BJ, Alagiri PS, Cestero RV. Crosssectional and longitudinal nutritional measurements in maintenance hemodialysis patients. Am J Clin Nutr 1981; 34:2005.

2. Wolfson M, Strong CJ, Minturn D, et al. Nutritional status and lymphocyte function in maintenance hemodialysis patients. Am J Clin Nutr 1984; 39:547.

3. Schoenfeld PY, Henry RR, Laird NM et al. Assessment of nutritional status of the National Cooperative Dialysis Study population. Kidney Int Suppl 1983:S80.

4. Keshaviah PR, Nolph KD, Moore HL, et al. Lean body mass estimation by creatinine kinetics. J Am Soc Nephrol 1994; 4:1475.

5. Marckmann P. Nutritional status of patients on hemodialysis and peritoneal dialysis. Clin Nephrol 1988; 29:75.

6. Buchwald R, Peña JC. Evaluation of nutritional status in patients on continuous ambulatory peritoneal dialysis (CAPD). Perit Dial Int 1989; 9:295.

7. Young GA, Kopple JD, Lindholm B, et al. Nutritional assessment of continuous ambulatory peritoneal dialysis patients: An international study. Am J Kidney Dis 1991; 17:462.

8. Owen WF Jr, Lew NL, Liu Y, et al. The urea reduction ratio and serum albumin concentration as predictors of mortality in patients undergoing hemodialysis. N Engl J Med 1993; 329:1001.

9. Lowrie EG, Lew NL. Death risk in hemodialysis patients: The predictive value of commonly measured variables and an evaluation of death rate differences between facilities. Am J Kidney Dis 1990; 15:458.

10. Aparicio M, Cano N, Chauveau P, et al, and the French Study Group for Nutrition in Dialysis (FSGND). Nutritional status of haemodialysis patients: a French national cooperative study. Nephrol Dial Transplant 1999; 14:1679.

11. Kopple JD, Greene T, Chumlea WC, et al. Relationship between nutritional status and the glomerular filtration rate: results from the MDRD study. Kidney Int 2000; 57:1688.

12. Garg AX, Blake PG, Clark WF, et al. Association between renal insufficiency and malnutrition in older adults: Results from the NHANES III. Kidney Int 2001; 60:1867.

13. Bammens B, Verbeke K, Vanrenterghem Y et al. Evidence for impaired assimilation of protein in chronic renal failure. Kidney Int 2003; 64:2196.

14. Lim VS, Ikizler TA, Raj DS et al. Does Hemodialysis Increase Protein Breakdown? 
Dissociation between Whole-Body Amino Acid Turnover and Regional Muscle Kinetics. J Am Soc Nephrol 2005; 16:862.

15. Lindsay RM, Spanner E, Heidenheim RP, et al. Which comes first Kt/V or PCR-Chicken or egg? Kidney Int Suppl 1992; 38:S32.

16. Rothstein RD, Alavi A. The evaluation of the patient with gastroparesis secondary to insulindependent diabetes mellitus (clinical conference). J Nucl Med 1992; 33:1707.

17. Grodstein G, Harrison A, Roberts C, et al. Impaired gastric emptying in hemodialysis patients (abstract). Kidney Int 1979; 16:952.

18. De Schoenmakere G, Vanholder R, Rottey S et al. Relationship between gastric emptying and clinical and biochemical factors in chronic haemodialysis patients. Nephrol Dial Transplant 2001; 16:1850.

19- Elhafiz M, Imam ME, Omran $O$ et al. Hemodialysis, plea of availability versus adequecy gezira experience. Sudan Journal of Medical Sciences. 2009;4(1):7-10.

20. NKF-K/DOQI Clinical Practice Guidelines for hemodialysis adequacy: update 2000. Am J Kid Dis 2001; 37:S7-S64.

21. Gotch FA, Sargent JA. A mechanistic analysis of the National Cooperative Dialysis Study (NCDS).Kidney Int 1985; 28: 526-534.

22. Laird NM, Berkey CS, Lowrie EG. Modeling success or failure of dialysis therapy: the National Cooperative Dialysis Study.Kidney Int 1983: 23 (Suppl 13) S101-S107.
23. Foley RN, Murray AM, Li S et al: Chronic kidney disease and the risk for cardiovascular disease, renal replacement, and death in the United States Medicare population, 1998 to $1999 . \quad \mathrm{J} \quad \mathrm{Am}$ Soc Nephrol 2005;16(2):489-495.

24. Ozkahya M, Toz H, Unsal A, et al. Treatment of hypertension in dialysis patients by ultrafiltration: Role of cardiac dilatation and time factor. Am J Kidney Dis 1999; 34:218.

25. Chazot C, Charra B, Laurent $C$ et al. Interdialysis blood pressure control by long haemodialysis sessions. Nephrol Dial Transplant 1995; 10:831.

26. McGregor DO, Buttimore AL, Nicholls MG et al. Ambulatory blood pressure monitoring in patients receiving long, slow home haemodialysis. Nephrol Dial Transplant 1999; 14:2676.

27. Covic A, Goldsmith DJ, Venning MC et al. Longhours home haemodialysis--the best renal replacement therapy method?. QJM 1999; 92:251.

28. Hakim RM, Levin N. Malnutrition in hemodialysis patients. Am J Kidney Dis 1993; 21:125.

29. Chertow GM, Ackert K, Lew NL, et al. Prealbumin is as important as albumin in the nutritional assessment of hemodialysis patients. Kidney Int 2000; 58:2512.

30. Chung SH, Lindholm B, Lee HB. Influence of initial nutritional status on continuous ambulatory peritoneal dialysis patient survival. Perit Dial Int 2000;20:19.

31. Kaballo B G, Idris M, Alhaj $H$ I et al. Psychological Disorders and Quality of Life among Sudanese Dialysis Patients and Renal Transplant Recipients. Sudan JMS Vol. 2010;5:29-34. 